\title{
"P'lo Sonho é que Vamos" Uma estratégia de inovação na promoção da cidadania de pessoas e comunidades ciganas
}

Ana Cardoso ${ }^{1}$

Heloísa Perista ${ }^{2}$

\begin{abstract}
$\mathrm{R}$ Lesumo: $\mathrm{O}$ artigo baseia-se no trabalho prático e reflexivo desenvolvido no âmbito do Projecto EQUAL "P'lo Sonho é que Vamos". Este Projecto tem como principais objectivos: ensaiar respostas para a conciliação da vida profissional, pessoal e familiar e o percurso escolar de pessoas ciganas; promover o diálogo intercultural entre comunidades ciganas e não ciganas, numa perspectiva de cidadania.

Parte de um conjunto de pressupostos básicos que salientam, por um lado, a necessidade de se adoptar um olhar plural sobre pessoas e comunidades ciganas, com padrões culturais muito marcados por papéis sociais de género; e que, por outro lado, reconhecem que as pessoas e comunidades ciganas são, ainda hoje, afectadas por graves problemas de integração social, económica, cultural e política, e por formas de pobreza extrema, exclusão e discriminação. Algumas actividades promovidas pelo Projecto "P'lo Sonho é que Vamos" são aqui discutidas e analisadas, numa lógica de inovação nas respostas sociais e de empowerment das mulheres ciganas.
\end{abstract}

Palavras-chave: Mulheres ciganas; Conciliação trabalho/vida pessoal e familiar/percurso escolar; Diálogo intercultural; Cidadania; Inovação; Empowerment.

O presente artigo baseia-se no trabalho prático e reflexivo desenvolvido no âmbito do Projecto "P'lo Sonho é que Vamos", iniciado em 2004 com financiamento da Iniciativa Comunitária EQUAL, que tem como principais objectivos: ensaiar respostas para a conciliação da vida profissional, pessoal e familiar e o percurso escolar de pessoas ciganas; promover o diálogo intercultural entre comunidades ciganas e não ciganas, numa perspectiva de cidadania. A Parceria de Desenvolvimento (PD) inicial do Projecto é constituída pela AMUCIP - Associação para o Desenvolvimento de Mulheres e Crianças Ciganas Portuguesas, a primeira e até agora única associação de mulheres ciganas em Portugal; CESIS - Centro de Estudos para a Intervenção Social; e DGACCP - Direcção-Geral dos Assuntos Consulares e das Comunidades Portuguesas / Ministério dos Negócios Estrangeiros. Vieram, ainda, a integrar esta parceria, em momento posterior, o Centro de Saúde do Seixal e o Centro Hospitalar do Baixo Alentejo, E.P.E.

\section{Diferentes abordagens, um mesmo olhar: sobre pessoas e comunidades ciganas}

Que conheçam cada cigano, porque nem todos são iguais" - esta é apenas umas das frases ditas quando mulheres ciganas tomaram a palavra no âmbito de uma recolha de testemunhos realizada e publicada pela AMUCIP (AMUCIP, 2006), uma iniciativa absolutamente inédita no nosso País que a então designada Comissão para a Igualdade e para os Direitos das Mulheres aprovou e financiou no âmbito dos apoios às Organizaçães Não Governamentais do seu Conselho Consultivo. Neste livro "Tomar a Palavra - Olhares e Falas de Mulheres Ciganas Portuguesas sobre a Família e o Trabalho"

\footnotetext{
Socióloga, investigadora do CESIS - Centro de Estudos para a Intervenção Social (www.cesis.org). Contacto: ana.cardoso@cesis.org

2 Socióloga, investigadora do CESIS. Contacto: heloisa.perista@cesis.org
} 
a AMUCIP dá conta da necessidade de se adoptar um olhar plural sobre pessoas e comunidades ciganas, atentando-se na sua diversidade e heterogeneidade. Como tem sido apontado por estudos neste domínio, "não existe uma etnoclasse cigana, mas sim vários estratos sociais ciganos que comungam, porventura com níveis de participação diferentes, uma mesma etnicidade e assumem uma identidade étnica comum mas que se pode expressar diferentemente "(Machado, in ACIME, 1997:7).

Utilizar o termo comunidade no plural $^{3}$ tem implícita esta noção confirmada pelo próprio desenvolvimento do Projecto. Nos contactos com vários interlocutores e na observação de diversas realidades concelhias (Seixal, Beja e Serpa) verifica-se, precisamente, essa pluralidade de vivências: há pessoas ciganas predominantemente sedentarizadas e outras para quem o quotidiano é marcado por uma (semi)itinerância; há famílias realojadas, residindo em habitações de tipologia clássica, ainda que normalmente em locais isolados, com difíceis acessibilidades e que não são servidos adequadamente por transportes públicos, mas mantém-se a presença de grupos de pessoas e famílias residindo em zonas muito degradadas onde persistem as más condições de higiene e conforto; há pessoas que não conheceram outra actividade económica para além da venda ambulante e outras cuja vida profissional foi vivida inteiramente na agricultura, no exercício de actividades agrícolas de carácter sazonal - em Portugal, mas também em Espanha, em particular na Andaluzia - nas colheitas do morango, do tomate, da laranja ou da azeitona.

A estes elementos de diferenciação acresce um outro que assume expressão particular no seio das diferentes comunidades e famílias ciganas, e que é induzido pela dimensão género. De facto, verifica-se uma forte predominância de padrões culturais muito marcados por papéis sociais de género, pelo que as vivências, designadamente familiares, e os percursos de vida e de trabalho são muito diferentes para mulheres e para homens ciganos bem como, desde cedo, para meninas e meninos e, sobretudo, para rapazes e raparigas e ciganas. Daqui decorre que, quando se fala de pessoas ciganas, há que falar de mulheres e de homens e, mais do que isso, adoptar de forma sistemática uma perspectiva de género.

$\mathrm{O}$ facto de a AMUCIP ser, até à data, a única associação de mulheres ciganas, num universo associativo cigano que (de acordo com os registos do ACIME - Alto Comissariado para a Imigração e as Minorias Étnicas) ultrapassa a dezena e meia de associações, é expressão de como estas mulheres experimentam contextos de socialização distintos e têm experiências de desigualdades marcadas por um silêncio naturalizado. Por outro lado, a estratégia de uma visibilidade discreta e prudente e as dificuldades de aceitação junto das próprias comunidades ciganas que a Associação conheceu no seu início (há cinco anos atrás) dão conta da emergência de uma certa "tensão" entre "etnia e género" (cf. McCarthy, 1994, in Cortesão, et al., 2005:15) certamente potenciadoras de mudança no interior das comunidades.

Entre as pessoas ciganas há já quem afirme: "deixem de olhar as mulheres como se fossem programadas para serem donas de casa, esposas e mães" (jovem, solteira de 19 anos, in AMUCIP, 2006:83) e essa foi, certamente, a leitura que inicialmente se fez do surgimento da AMUCIP para quem o início não foi fácil, decorrente da "oposição tanto das comunidades ciganas como não ciganas" (de acordo com as palavras da Presidente da AMUCIP). Talvez reforçadas pela convicção de que "ninguém melhor do que os próprios membros das comunidades ciganas pode transformar as realidades quotidianas das suas mulheres e filhas", os elementos da AMUCIP, apoiadas pelo Projecto "P'lo Sonho é que Vamos" estão, a pouco e pouco, construindo uma "cultura de compromisso" (cf. Charlot, 1999, in Cortesão, et al., 2005:15) que lhes permite conciliar e viver "dentro de duas culturas" (Casa-Nova, 1999 in Cortesão, et al., 2005:15): "podemos sempre fazer o que queremos sem deixar de ser o que somos" (Presidente da AMUCIP).

\section{Exclusões versus cidadania}

Independentemente dos factores que se podem constituir como elementos de diferenciação,

${ }^{3}$ Para além da própria pluralidade de definições que dá conta da inexistência de consenso em torno do conceito. 
as comunidades ciganas partilham, porém, uma situação de exclusão que, segundo alguns autores (cf. Machado, in ACIME, 1997) assume o carácter de uma exclusão secular. Na esteira de uma história de discriminação e mesmo de perseguição, tanto a nível nacional como da Europa (cf. Comissão Europeia, 2004), as comunidades ciganas são, ainda hoje, afectadas por graves problemas de integração social, económica, cultural e política, e por formas de pobreza extrema, exclusão e discriminação (conforme salientado por Odile Quintin, Directora-Geral do Emprego, Assuntos Sociais e Igualdade de Oportunidades, na Comissão Europeia, em discurso proferido em 25 de Janeiro de 2005, no Fórum Cigano do Parlamento Europeu).

Atente-se, por exemplo, na situação escolar das comunidades ciganas. Com efeito, apesar das crianças estarem hoje, na sua maioria, matriculadas na escola (na sequência, nomeadamente, da elaboração dos programas de inserção do Rendimento Social de Inserção - RSI e, anteriormente, do Rendimento Mínimo Garantido - RMG), o seu percurso escolar continua a ser caracterizado, em muitos casos, pelo insucesso - pelas dificuldades de adaptação destas crianças à escola mas também pelas dificuldades de adaptação da escola a estas crianças $^{4}$ - e pelo abandono escolar precoce ${ }^{5}$. São muito poucos os rapazes ciganos que prosseguem os estudos para além do $1 .^{\circ}$ ciclo do ensino básico e são ainda menos (quase nenhumas) as raparigas ciganas que o fazem ${ }^{6}$. Por um lado, porque estas raparigas são desde cedo chamadas a participar nas tarefas domésticas e no cuidado dos irmãos e irmãs mais novas, até como forma de se prepararem para o seu próprio papel de mulheres casadas e mães. Mais do que isso, por outro lado, porque as meninas ciganas, uma vez atingida a puberdade, 'serão faladas' se continuarem na escola.

Sabemos que entre as comunidades ciganas prevalece um sistema de endoculturação a nível da família nuclear e alargada e uma recusa em delegar as tarefas educativas em qualquer instituição, até aos 6/7 anos (vd. Cruz, 2004). Esta norma cultural de, pelo menos nos primeiros anos de vida, as crianças não deverem estar longe do olhar 'protector' de familiares faz com que a creche e o jardim de infância sejam geralmente considerados desadequados e encarados com desconfiança o que coloca as crianças ciganas, cada vez mais, numa clara desvantagem face aos outros na entrada para a escola.

Por outro lado, entre estas comunidades há uma dificuldade em "conceber uma forma de educação desligada da vida concreta: familiar, grupal, social e económica" parecendo difícil que algo prepare para a vida sem ser a própria vida" (Amiguinho, 1999:47).

Estes traços culturais associados a preconceitos e práticas discriminatórias por parte do próprio sistema educativo (Conselho da Europa, 2005), bem como a condições de grande pobreza traduzem-se em desigualdades no acesso à educação por parte das crianças ciganas, tal como é reconhecido a nível europeu. Embora graves e comuns a todos os países da União Europeia, estas desigualdades ainda não encontram eco ao nível dos respectivos sistemas e estratégias de ensino, nem ao nível da valorização e motivação para a aprendizagem (Comissão Europeia, 2004).

Para além de tudo o que se possa fazer no sentido da implementação de um verdadeiro sistema de ensino-aprendizagem intercultural, afigura-se, também, crucial promover a consciencialização das mães e dos pais ciganos, a maior parte dos quais não frequentaram a escola, sobre a necessidade e os benefícios da escolaridade para os seus filhos e, em particular, para as suas filhas. Para além disso, num contexto cultural de desvalorização da escola, urge definir estratégias específicas de motivação para a frequência do ensino por parte das crianças e jovens ciganos, tanto do sexo masculino, como do sexo feminino, 'cativando-os', por exemplo, através de formas de expressão artística, como a música ou a dança.

No âmbito do Projecto "P'lo Sonho é que Vamos", este tem sido um papel fundamental da

\footnotetext{
${ }^{4}$ Como tem sido demonstrado e desconstruído por iniciativas tais como o Projecto Nómada, promovido desde 1995 pelo ICE - Instituto das Comunidades Educativas.

${ }^{5}$ A este respeito, a falta de higiene pessoal é frequentemente referida, nos concelhos do Alentejo, como problema que agrava a relação das crianças com a escola.

${ }^{6}$ No ano lectivo de 2003/04 estavam matriculadas no sistema de ensino 9335 crianças de etnia cigana, sendo que $88 \%$ frequentavam o $1 .^{\circ}$ ciclo do ensino básico, de acordo com os dados publicados pelo Gabinete de Informação do Sistema Educativo.
} 
AMUCIP com o "Espaço de Apoio à Conciliação das Pessoas Ciganas", no Bairro da Cucena (Seixal). Neste Espaço, para além da necessária articulação com outras entidades locais, nomeadamente as escolas, decorrem actividades como o apoio escolar informal; atelier de dança e de teatro. Nele são abrangidas 20 crianças em idade escolar, a maior parte das quais raparigas; 12 jovens e 15 famílias e o mesmo tem-se assumido como uma alternativa a uma vida de isolamento, para umas, e de incentivo efectivo à frequência da escola:

"Se não existisse o 'Espaço' eu passava as tardes em casa, porque nem sempre me deixavam sair de casa pois com a minha idade não posso andar na rua como as minhas irmãs mais novas" (Tâmara, 14 anos).

"Desde que vim para aqui a minha vida mudou, porque com a ajuda das monitoras consegui ir para a escola. Fizeram-me a matrícula e levaram a minha avó de carro porque não havia transporte. Agora quando saio da escola, tenho um sítio para onde ir" (Débora, 9 anos).

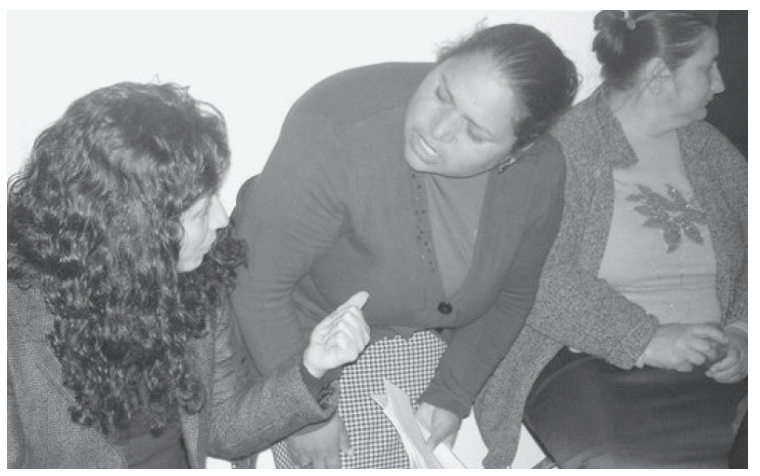

Este é um serviço adaptado aos ritmos de vida, desejos e vivências das comunidades ciganas. Ali fala-se de "cigana para cigana" e, com uma confiança que é gerada na ideia de que "elas são umas de nós", se salienta a importância da escola para alcançar outras formas de vida que começam a ser desejadas (e exigidas) face à evidente falência de uma vida muito dependente da venda ambulante.

A cultura cigana tem-se pautado por uma recusa sistemática de submissão às regras do mercado de trabalho capitalista e por um distanciamento do tipo de racionalidade que o sustenta, evidenciando assim uma forte recusa da proleta- rização (cf. Magano e Silva, 2000; Cortesão, et al., 2005), à qual se associa, sem dúvida, a relutância por parte de muitas entidades empregadoras em contratarem pessoas ciganas - a persistência de preconceitos e atitudes discriminatórias no emprego, face a pessoas ciganas é, aliás, reconhecida como um problema grave pelas instâncias comunitárias (cf. Comissão Europeia, 2004; Conselho da Europa, 2005). No entanto, começa a ser evidente o surgimento de novas necessidades a este nível, na sequência da compressão cada vez mais visível das ofertas criadas pelas actividades económicas tradicionais.

Essa compressão, de facto, é exercida por várias frentes. A venda ambulante é cada vez mais reprimida pelas forças policiais e objecto de controlo por parte das autoridades locais; as feiras e mercados têm vindo a desaparecer ou a perder importância. Por outro lado, novas lógicas de preços são introduzidas pela proliferação das grandes superfícies, bem como pelo alastramento de lojas geridas por imigrantes de origem asiática que entram em concorrência com os preços tradicionalmente praticados pelos vendedores e vendedoras ciganos.

Também em relação às actividades agrícolas sazonais, particularmente em Espanha, os cidadãos e as cidadãs ciganas portuguesas se vêm confrontadas com a concorrência acrescida de imigrantes do Magrebe e do Leste da Europa, aos quais é dada preferência pelas entidades empregadoras, até porque, ao contrário das famílias ciganas, se deslocam sozinhos, sem levar consigo toda a família, crianças incluídas - como é do conhecimento e como constitui preocupação da Direcção-Geral dos Assuntos Consulares e Comunidades Portuguesas e da rede consular portuguesa em Espanha (em particular o Consulado em Sevilha), atenta às suas atribuições em matéria de apoio a trabalhadores e trabalhadoras portuguesas no estrangeiro, designadamente no que diz respeito ao direito comunitário aplicável em matéria de liberdade de circulação de trabalhadores ${ }^{7}$.

Assim, neste contexto de compressão, senão mesmo de destruição, das oportunidades de trabalho tradicionais, muitas mulheres e homens ciganos

\footnotetext{
Nos concelhos de intervenção do projecto, no Alentejo, há actualmente menos famílias ciganas a participar nas campanhas agrícolas sazonais em Espanha.
} 
começam a ambicionar outro "futuro" e aspirar "para os seus descendentes um futuro que não passe pela "venda"" (Dias, Eduardo Costa, et al., 2006:92) ${ }^{8}$. No entanto, esta aspiração é confrontada com a ausência de formação escolar e/ou profissional, experiência ou tradição profissional que lhes permitam facilmente construir novos projectos profissionais.

No contexto do Projecto, foram identificadas, através da AMUCIP, 103 pessoas ciganas, que traduzem um exemplo de uma nova atitude nem sempre facilitada pelas circunstâncias. São homens e mulheres, com idades compreendidas entre os 15 e os 64 anos, que reconhecem as suas baixas qualificações e que as pretendem aumentar para poderem encetar, mudar ou melhorar o seu percurso profissional e/ou de vida. No grupo conta-se com a presença de três mulheres ciganas viúvas o que, por si só, representa um sinal de abertura das famílias e uma capacidade de mudança dos indivíduos.

Porém, o enquadramento destas pessoas nas medidas de formação e emprego disponíveis torna-se difícil, pelo seu quadro de vida, pelas suas carências económicas e, sobretudo, por alguns traços da sua cultura. Embora se considere correcto o caminho da não pulverização de medidas de natureza específica que, por vezes, são tendentes a uma acentuação de estigmas sociais, também é certo que não se "pode tratar igual, aquilo que é diferente" sob pena de as desigualdades se acentuarem pela não criação efectiva de condições de igualdade de oportunidades. A pergunta é se, de facto, essas condições foram já criadas no que diz respeito à população cigana. Note-se que, apesar do impacto do RMG/RSI em termos do acesso de mulheres e homens ciganos a cursos de formação profissional, um estudo sobre $O$ jovem cigano e a formação (Reis, 1999) demonstra que, na sua maioria, estes e estas jovens ${ }^{9}$ nunca frequentaram qualquer acção de formação profissional. Por outro lado, e tal como se refere em Dias, Eduardo Costa, et al. (2006:94) as políticas de formação e emprego "para além de não terem em consideração o estigma que sobre os ciganos impera desde há séculos, apontam em exclusivo para a sua integração na dita sociedade de modelo salarial" onde a adaptação é, ainda, difícil.

Pobreza, baixos níveis de instrução e deficientes condições de alojamento - muitas são as pessoas que ainda vivem em barracas improvisadas, sem água, luz ou esgotos, e apesar dos realojamentos que nos últimos anos se têm verificado, muitos, como aconteceu recentemente em Beja, por exemplo, constituem espaços guetizados e desprovidos de estabelecimentos comerciais, equipamentos e serviços - "aliadas a uma discriminação persistente na provisão de serviços de saúde, têm levado a uma elevada incidência de doenças transmissíveis, tais como a tuberculose e a hepatite, havendo uma forte evidência de uma esperança de vida mais reduzida" (Comissão Europeia, 2004) entre as comunidades ciganas.

Em Portugal a relação das pessoas ciganas com as estruturas de saúde é "caracterizada por sentimentos de exclusão. As queixas apresentadas são muitas: dos médicos e dos medicamentos (...). Mas, contudo, notam-se já algumas formas de integração pela atitude preventiva como, por exemplo, a vacinação, as consultas de rotina dos bebés, ou, em caso de dúvida, o recurso à consulta do serviço de urgência". (Magano e Silva, 2000.)

No sentido de contrariar a 'distância' que ainda se verifica entre pessoas ciganas e serviços de saúde, têm surgido iniciativas como o projecto Saúde sobre Rodas. Este projecto, que funciona desde 2004 no concelho do Seixal, é promovido por uma parceria entre diversas instituições do concelho, entre as quais o Centro de Saúde do Seixal. Tem como principais objectivos promover o acesso aos centros de saúde e ao hospital e educar para a prevenção no âmbito da saúde materno-infantil, deslocando-se aos locais de residência das pessoas.

Embora ainda fortemente pautada por uma "inconformidade aos papéis sociais de doente e utente dos serviços ${ }^{10}(\ldots)$ (parecem contudo

\footnotetext{
${ }^{8}$ Embora o estudo citado citado não possa ser considerado como representativo (foram realizadas apenas 21 entrevistas) ele aponta para uma nova tendência dentro de uma franja da população cigana que não deve ser descurada.

9 Neste estudo foram inquiridos 200 jovens, correspondendo ao total de jovens ciganos, de ambos os sexos, com idades compreendidas entre os 16 e os 25 anos, residentes nos bairros do Zambujal (Amadora); Quinta da Fonte (Loures); Portugal Novo, Quinta das Laranjeiras e Vale do Forno (Lisboa).

${ }^{10}$ Tão sentida e que tanto se faz sentir, designadamente, no Centro Hospitalar do Baixo Alentejo.
} 
registar-se) tendências no sentido da mudança de atitudes e comportamentos de saúde (...) assente no pragmatismo da adesão ao que faz prova de 'bons resultados" (Silva, s.d.: 78). Adere-se, assim, à contracepção, ao parto hospitalar, às consultas pré e pós-natais, à vacinação das crianças, o "que não acontecia com as gerações anteriores" (Cruz, 2004: 140).

Mas se adesão a (alguns) cuidados de saúde começa a ser frequente entre as comunidades ciganas, o que marca a sua relação com os serviços de saúde é, sobretudo, uma dimensão "comportamental" baseada na ideia de que "os ciganos se recusam a cooperar nas mais elementares regras de coexistência social" e que fazem uma "rejeição das normas de utilização dos serviços de saúde" (Duarte, coord., 2005:97).

Nos Centros de Saúde o tipo de cuidados prestados, e as situações não agudas de doença que atendem, facilita relações mais douradoras e continuadas, o que por sua vez estimula a confiança e a aproximação (ainda que lenta) entre profissionais e utentes ciganos, o que não significa que a presença destes não seja sentida de "modo intrusivo e abrupto" por parte dos técnicos de saúde (Duarte, coord., 2005:74).

Esta incomodidade será, porém, mais sentida nos Hospitais onde as relações de natureza mais pontual e as situações críticas de doença, e mesmo de morte, acentuarão aquela incapacidade de lidar com as regras que, no fundo, decorre da noção de que um hospital é universo impenetrável de separação entre a vida e a morte, entre o conhecido e o desconhecido.

É o que acontece no Centro Hospitalar do Baixo Alentejo, onde a presença de população cigana nos serviços, tem, em muitos casos, sido considerada como perturbadoras, por vezes de modo grave, quer por parte de doentes não ciganos e suas famílias, quer por parte do Conselho de Administração e de profissionais do Centro Hospitalar: "Eles (ciganos) juntam aqui a família toda, fazem muito barulho e exigem entrar".

Neste contexto, a intervenção no campo da saúde poderá ser "incentivada mediante a acção informativa de cariz intercultural, capaz de fazer dialogar os conhecimentos médicos e a sua lógica preventiva com as concepções leigas das lógicas culturais Ciganas" (Silva, s.d.). Esta necessidade de interlocução intercultural é fortemente sentida e expressa, designadamente, pelo Centro Hospitalar do Baixo Alentejo, E.P.E.

No mesmo sentido, é referida como boa prática a nível europeu a formação e consequente contratação pelos serviços de saúde de mediadores ciganos para esses serviços, no sentido de facilitar a relação entre estes e as famílias ciganas, em particular, no que respeita à promoção da saúde materno-infantil (cf. Comissão Europeia, 2004).

É precisamente, neste sentido, que, no âmbito do Projecto, aquele Centro Hospitalar está a encetar um processo de formação em contexto de trabalho, seguida da respectiva contratação, de um mediador e de uma mediadora ciganos. Este processo surge após a formação ministrada a um grupo de profissionais do Centro Hospitalar (administrativos/as; pessoal de serviço social e de enfermagem) sob o título "Cidadania, Igualdade de Género e Interculturalidade em Serviços de Saúde", que contemplava um módulo de formação sobre cultura cigana, cujas formadoras foram elementos da AMUCIP ${ }^{11}$. No dizer de uma das formandas, profissional de saúde: "o facto de termos passado a conhecer aspectos centrais da cultura cigana, com a apresentação de testemunhos pessoais, permite-nos estabelecer uma comunicação mais acessível".

Outra estratégia accionada pelo Centro Hospitalar, ainda no âmbito da sua participação no Projecto, tem sido a organização de “Tertúlias de Cruzamento de Saberes" sobre diferentes temas ligados à saúde materno-infantil, as quais têm sido dinamizadas por enfermeiras do Centro Hospitalar, mas nas quais se dá oportunidade e se criam as possibilidades para as participantes expressarem os seus receios, crenças e preconceitos face às doenças e aos tratamentos propostos. Estas tertúlias têm sido cuidadosamente preparadas e têm contado com a participação de mulheres da AMUCIP com o objectivo de se adaptar as linguagens e se acentuar a importância das imagens e de ajudar a criar todo um clima que facilite o diálogo. Algumas destas tertúlias têm acontecido no espaço do próprio

${ }^{11}$ Uma das primeiras acções do Projecto foi a organização de um curso de Formação Inicial de Formadores/as, dirigido preferencialmente a elementos da AMUCIP. Este curso foi possível na sequência de uma parceria com o IEFP - Centro Nacional de Formação de Formadores. 
Hospital, ajudando a humanizar a sua imagem aos olhos das comunidades; outras têm decorrido no Bairro da Esperança e no novo Bairro das Pedrei$\operatorname{ras}^{12}$, facilitando uma relação de proximidade, confiança e cooperação entre serviços e público destinatário. Como ilustração refira-se a afirmação de uma enfermeira participante das tertúlias: "No outro dia, uma mulher cigana que tem estado nas tertúlias cruzou-se comigo na rua e cumprimentou-me!"

O mesmo tipo de tertúlias, com objectivos semelhantes, tem tido lugar com a participação do Centro de Saúde do Seixal, algumas no espaço do Centro de Saúde, outras na sede da AMUCIP, no Bairro da Cucena.

Estes são, certamente, bons exemplos de adaptação dos serviços às necessidades das comunidades ciganas (cf, Quintin, 2005), contribuindo-se, desta forma, para o acesso destas populações ao direito (neste caso) à saúde que lhes assiste.

Procura-se, assim, ultrapassar alguns dos múltiplos factores que, em múltiplos domínios, se constituem como factores de exclusão. Os domínios atrás referidos - educação e formação, trabalho, saúde - são bem reveladores do 'fosso' entre os direitos legalmente consagrados e as condições efectivas de exercício desses direitos. Importa não esquecer que é, desde logo, a Constituição da República Portuguesa, no seu artigo $13 .^{\circ}$ (Princípio da Igualdade), que estabelece que ${ }^{13}$ :

1. Todos os cidadãos têm a mesma dignidade social e são iguais perante a lei.

2. Ninguém pode ser privilegiado, beneficiado, prejudicado, privado de qualquer direito ou isento de qualquer dever em razão de ascendência, sexo, raça, língua, território de origem, religião, convicções políticas ou ideológicas, instrução, situação económica, condição social ou orientação sexual.
Também ao nível europeu se tem assistido à adopção de importantes instrumentos legais, no sentido da garantia do respeito pelos direitos humanos das pessoas ciganas, nomeadamente no âmbito do Conselho da Europa, mas também da União Europeia (dos quais é exemplo recente a Directiva do Conselho 2000/43/EC, implementando o princípio da igualdade de tratamento entre as pessoas independentemente da sua origem racial ou étnica).

Por outro lado, estamos actualmente em pleno Ano Europeu para a Igualdade de Oportunidades entre Todos e assistimos recentemente ao lançamento da Década para a Inclusão das Pessoas Ciganas, iniciativa que abrange oito países da Europa Central e de Leste e que conta com a participação da Comissão Europeia ${ }^{14}$.

Mas é também a nível europeu, bem como a nível nacional, que se reconhece a relativa inoperância e inefectividade de muitas disposições legais (em relação às pessoas e comunidades ciganas tal como, aliás, em relação a outros grupos sociais em situação de desfavorecimento). As próprias respostas políticas apresentam-se muitas vezes inadequadas e incoerentes, exemplo disso será o facto de que muitos Estados-Membros da União Europeia (entre os quais não se conta Portugal), com comunidades ciganas numerosas, as identificarem como um grupo vulnerável e não definirem explicitamente as pessoas ciganas como grupo-alvo dos seus Planos Nacionais de Acção para a Inclusão (cf. Comissão Europeia, 2004).

Parece, assim, inegável que "as pessoas ciganas ainda não usufruem dos seus plenos direitos enquanto cidadãs da UE.” (Quintin, 2005). 'Cidadãos do mundo', como muitos/as lhes têm chamado, vêem-se excluídos de um conceito de cidadania que "foi construído com base nas sociedades nacionais e os ciganos, ao não participarem nessas sociedades, adquirem uma cidadania feita de exclusão, uma cidadania que fica por cumprir já que não é garantida a equidade que permita quer a melhoria

\footnotetext{
12 Espaço de realojamento de famílias ciganas até então vivendo em barracas no Bairro da Esperança.

13 Contudo, importa referir também que, tal como é apontado por estudos feitos neste domínio (cf. Pinto, 2000), no final do século Xx subsistia em Portugal um procedimento legislativo discriminatório face às pessoas ciganas - trata-se de um dos artigos do Regulamento da Guarda Nacional Republicana, aprovado em 1985, que permite o exercício de vigilância especial sobre os nómadas por se entender que a sua mobilidade e carência económica favorecem as práticas criminais - havendo uma nítida associação entre pessoas nómadas e pessoas ciganas.

14 A este propósito, e independentemente das dimensões relativas das comunidades ciganas em presença e dos respectivos problemas específicos, considera-se prejudicial para a situação, o progresso e a defesa de direitos e de interesses das comunidades ciganas em outros Estados-membros do Conselho da Europa, incluindo Portugal, que a iniciativa não seja alargada, com os ajustamentos adequados, a todos aqueles Estados onde existem comunidades ciganas.
} 
das condições de vida, quer a alteração da subalternidade" (Pinto, 2000:133).

\section{Preconceitos e diálogo(s)}

"Elas (profissionais de um determinado serviço) não nos deixam falar, falam muito depressa e numa língua que a gente não percebe, é do sotaque" - fala de uma mulher cigana num grupo de discussão realizado aquando do diagnóstico do Projecto.

"Entendem! Eles (os ciganos) só não entendem o que não querem e quando não querem" - observação de uma profissional de um serviço público num grupo de discussão realizado aquando do diagnóstico do Projecto.

O cruzamento das duas frases anteriores dá conta de uma incapacidade para o diálogo, bem como da distância entre as pessoas ciganas e a sociedade em geral e do distanciamento desta e, em particular dos serviços, em relação às pessoas ciganas.

Esta questão não se pode dissociar da estigmatização acrescida de que as comunidades ciganas têm sido vítimas, nos últimos anos, a qual "atinge não indivíduos em particular, mas todo o corpo social, gerando comportamentos hostis e de rejeição por parte das comunidades locais" (Bacelar de Vasconcelos, in Montenegro, org., 1999:14).

Para além de uma associação dos colectivos ciganos à prática de actividade ilícitas está em questão, em particular nos concelhos do Alentejo abrangidos pelo Projecto, o incumprimento, por parte de pessoas ciganas, dos acordos de inserção do Rendimento Social de Inserção, nas áreas do emprego e da educação, bem como a propensão para omitir informação relevante quanto aos rendimentos.

A generalização desta ideia em concelhos envelhecidos e economicamente deprimidos (como é o caso de Serpa) onde a população maioritariamente idosa vive de pensões com valores muito baixos, "apesar de terem trabalhado toda uma vida" cria um sentimento de injustiça face à atribuição do RSI a pessoas que, na sua opinião, "não fazem nada" e se "limitam a viver na dependência dos subsídios".

Como sublinha o Conselho da Europa na sua página electrónica relativa a pessoas ciganas e nómadas, "parece que a situação difícil em que se encontram numerosas comunidades ciganas e nómadas representa a prazo um risco para a coesão social dos Estados-membros" (Nota de abertura $\S 3)$.

O papel das autoridades locais, bem como de instituições várias a nível local, reveste-se, assim, de enorme importância, designadamente promovendo ou refreando a implementação de políticas desenhadas a nível nacional dirigidas à inclusão social das pessoas e comunidades ciganas (cf. Comissão Europeia, 2004). Tal como sublinhado pelo Comissário para os Direitos Humanos, “em muitos países, observei que as autoridades locais, especialmente aquelas que detêm cargos eleitos, se mostram muitas vezes pouco disponíveis para implementarem medidas propostas no âmbito de programas nacionais com receio de se tornarem impopulares aos olhos da população maioritária, ou por vezes devido às suas próprias atitudes discriminatórias" (Conselho da Europa, 2005).

Essa impopularidade traduz um "sentimento anti-cigano" identificado pela própria Comissão Europeia (2004) como sendo uma realidade presente na maioria, senão em todas, as sociedades europeias, sendo particularmente agudo em alguns países. Por outro lado, em relatório muito recentemente editado pelo Conselho da Europa, da autoria do Comissário para os Direitos Humanos, Álvaro Gil Robles, reconhece-se uma deterioração desta situação nos últimos anos, "em parte devida aos impactes sociais da transição económica na última década, mas também devida a um clima de intolerância crescente, particularmente evidente desde 2001. Uma nova vaga de atitudes anti-ciganos parece ter emergido em alguns países da Europa Ocidental, com especulações dos media sobre imigração em larga escala de pessoas ciganas da Europa de Leste na sequência do alargamento da União Europeia" (Conselho da Europa, 2005).

E, como o mesmo Relatório refere, estes sentimentos estão de tal forma enraizados que contribuem para a banalização e aceitação generalizadas da discriminação a que as pessoas ciganas são sujeitas: "a discriminação não é uma questão que afecte uma área particular da vida, mas que se manifesta de várias formas na vida pública e privada, e que é frequentemente alimentada por estereotipificação nos media e até nas declarações 
de responsáveis públicos. Os sentimentos anti-ciganos estão de tal forma enraizados em algumas sociedades que a discriminação contra as pessoas ciganas em áreas como o emprego, a educação, o alojamento ou o acesso aos serviços e equipamentos públicos parece ser geralmente tolerada, e não considerada ilegal" (Conselho da Europa, 2005).

Embora presentes em Portugal há pelo menos cinco séculos, as comunidades ciganas têm conseguido preservar a sua cultura e modo de vida, quase sempre à margem da sociedade, o que terá contribuído para a sua tão vincada exclusão social (cf. Magano e Ferreira da Silva, 2000). Esta cultura forte, marcada entre outros aspectos, por um acentuado 'viver o dia-a-dia', sem investimento no futuro (cf. Comissão Nacional do Rendimento Mínimo, 1998) ou, por outras palavras, por um modo polícrono de viver os espaços e os tempos (cf. Montenegro, in Montenegro, org., 1999) tem potenciado que a generalidade das pessoas ciganas, apesar da sua crescente diferenciação, se continue "a reconhecer numa identidade cultural assente num código de honra específico, numa língua o "caló", na procura de manutenção de uma identidade própria, face ao não cigano que se procura manter afastado das regras da vida que regem as relações entre os ciganos" (ACIME, 1997:9).

Não se trata de negar ou pôr em questão a identidade e a cultura ciganas, antes sim de lhes dar visibilidade e reconhecimento, de modo a favorecer o diálogo intercultural. "A educação e a consciencialização sobre a cultura e as tradições ciganas são vitais para a prossecução deste objectivo (o de garantir o respeito integral do princípio da não-discriminação), dado que a intolerância é frequentemente gerada por falta de conhecimento. (...) Iniciativas que promovam a interacção entre populações ciganas e não ciganas são também de enorme importância" (Conselho da Europa, 2005).

Foi neste sentido que o Projecto, integrou num programa de formação especificamente concebido para abranger cerca de 70 pessoas, profissionais de vários serviços pertencentes às Redes Sociais de Beja, Serpa e Seixal e do Centro Hospitalar do Baixo Alentejo, como atrás se mencionou, um módulo de formação sobre cultura cigana. Este módulo, preparado pelos elementos da AMUCIP, ainda que com o apoio e suporte dos restantes membros que integram a Parceria de Desenvolvimento do Projecto, e ministrado pelas mesmas, enquanto formadoras devidamente formadas e certificadas para o efeito, numa acção também ela inovadora desenvolvida pelo IEFP já no quadro do Projecto, teve um forte impacto.

Para além do aumento das competências e da auto-confiança das cinco mulheres ciganas envolvidas directamente neste processo, esta formação significou uma inversão de papéis e de posições; implicou um reconhecimento e o respeito pelas formadoras o que, em si mesmo, desfaz preconceitos e cria proximidades; revelou desconhecimentos e obrigou a outros olhares por parte de quem, normalmente, fundamenta os seus juízos de valor; obrigou a que cada um e cada uma se identificasse como agente de discriminação, mas também como agente de mudança sendo que essa mudança deve começar, antes de mais, por uma mudança de atitude no processo de comunicação com o /a utente.

É também no sentido de favorecer o diálogo inter-cultural e o aprofundamento da cidadania que se tem vindo a promover uma série de tertúlias de cruzamento de saberes, na sede da AMUCIP, sobre temas vários, tais como a qualidade de vida no Bairro, o acesso das raparigas e mulheres ciganas à educação e à formação, novas alternativas de trabalho e emprego para pessoas ciganas.

Sabiamente, algumas mulheres ciganas apontam no mesmo sentido do Projecto:

"Que somos todos iguais... O sangue é todo vermelho... A única coisa diferente é a cultura... E se nos conhecêssemos melhor... Talvez não discriminássemos tanto..."

"Que devemos dar um passo, parte a parte, ciganos e não ciganos, e no fundo o que nos diferencia é apenas a cultura... Temos que respeitar os outros, com as nossas diferenças" (AMUCIP, 2006: 83, 86).

\section{O empowerment necessário}

“O tratamento desigual não é sempre resultado de discriminação intencional ou de atitudes racistas, podendo resultar de estruturas societais que respondem sobretudo às necessidades da população maioritária, sem prestar atenção suficiente às necessidades particulares que populações mino- 
ritárias possam ter. Em larga medida, isto resulta da ausência de membros de minorias nos processos de tomada de decisão" (Conselho da Europa, 2005).

É também por isso que orientações recentes, nomeadamente a nível da Comissão Europeia, identificam como objectivo prioritário o encorajamento das pessoas ciganas para assumirem a responsabilidade pelo seu próprio desenvolvimento (Quintin, 2005). "As organizações ciganas têm um papel a desempenhar na promoção do seu próprio bem-estar participando nas sociedades na medida das suas capacidades, e contribuindo para a eliminação de preconceitos e estereótipos" (Comissão Europeia, 2004). Neste mesmo sentido, as associações e organizações ciganas deverão, também, envolver-se activamente em iniciativas para a promoção de monitoria étnica, como meio de identificação de problemas, fundamentação de políticas específicas e avaliação de impacto (idem). Tais processos de monitoria deverão integrar de forma deliberada a dimensão do género, de modo a evidenciar as diferentes situações e processos vividos por mulheres e homens ciganas/os.

Por outro lado, os próprios "governos deveriam incorporar uma perspectiva de género nas suas estratégias dirigidas às pessoas ciganas, com base em investigação rigorosa que identifique adequadamente os interesses e as questões que afectam as mulheres, para além do seu papel tradicional de prestação de cuidados maternais" (Comissão Europeia, 2004).

Estas serão estratégias possíveis ${ }^{15}$ para garantir que "os ciganos (que) consideram que quem sabe da sua cultura e da sua forma de vida são eles próprios (e que enquanto) directamente interessados (...) deverão ser os principais conceptores e organizadores dos seus próprios projectos, ainda que para isso precisem do nosso apoio" (Amiguinho, 1993).

Esta foi, de facto, a estratégia seguida pelo Projecto, que integra na sua Parceria de Desenvolvimento a AMUCIP como seu membro de pleno direito e não única e exclusivamente como uma entidade destinatária das suas acções. Atente-se que o facto da AMUCIP ser uma associação de mulheres ciganas tem um significado duplo dado que as mulheres ciganas enfrentam ainda maiores dificuldades do que quer os homens ciganos quer as mulheres da comunidade maioritária no acesso a um conjunto de direitos sociais e, nomeadamente, ao direito à participação social.

Assim, a presença da AMUCIP na parceria tem constituído um autêntico processo de promoção de empowerment aos seus diferentes níveis:

- Individual - porque se promovem as competências pessoais dos elementos da Associação, em particular através de um programa de formação contínua e à medida, que atravessa todo o desenvolvimento do Projecto e que toca três grandes temas centrais: a AMUCIP enquanto associação; a AMUCIP enquanto entidade empregadora; a AMUCIP enquanto agente de intervenção social.

- Colectivo - porque se reforça a capacidade de iniciativa e de efectiva concretização de grupo de pessoas enquanto organização colectiva que, neste momento, é reconhecida como elemento activo das parcerias locais. Refira-se aqui o grande questionamento que a AMUCIP mereceu por parte de outras entidades, do Concelho do Seixal, quase que inteiramente financiadas por dinheiros públicos, sobre a sua capacidade de garantir sustentabilidade às acções que entretanto iniciavam. Se esta é, de facto, uma questão que a todos deve preocupar e, em primeiro lugar à própria AMUCIP, esta é uma pergunta que revela as dificuldades de afirmação de uma pequena "associação de base" e que traduz as relações de poder entre instituições e o questionamento a hierarquias instaladas que o empowerment vem favorecer.

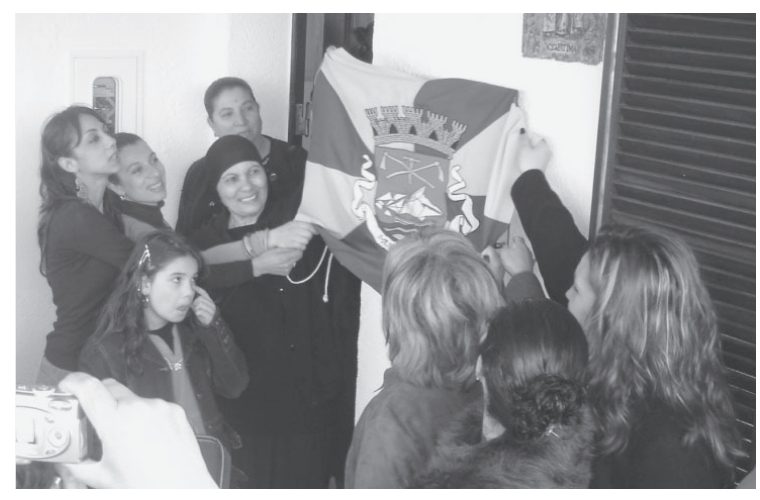

${ }^{15}$ Embora nem sempre fáceis de implementar: por exemplo, no concelho de Beja, as instituições locais dizem não conseguir encontrar formas de interlocução com as comunidades ciganas, não estando estas organizadas nem evidenciando lideranças claras. 
- Comunitário - porque se contribui para a capacidade de resolução de problemas de uma comunidade por parte de elementos dessa mesma comunidade.

Ser elemento de uma Parceria de Desenvolvimento no âmbito de um Projecto financiado pela Iniciativa Comunitária EQUAL é em si mesmo um grande desafio para qualquer organização. A AMUCIP ser membro de uma Parceria de Desenvolvimento - e logo no primeiro projecto europeu em que participa - constitui um desafio ainda maior para a própria bem como para os restantes parceiros.

Para a própria Associação porque um projecto, pensado e implementado de acordo com uma metodologia de planeamento, faz romper com aquilo que são alguns dos traços fortes do quotidiano das pessoas ciganas:

- Definição de objectivos que são para cumprir, ainda que se possam redefinir à luz de alterações dos contextos de implementação - "como é possível se não sei o que será o dia de amanhã?"

- Programação de trabalho, calendarização de reuniões e de encontros - "mas o povo cigano não tem agenda" e mesmo depois de se ter agenda, no início, ela perde-se, trocam-se os meses e suspira-se "não quero marcar mais nada!"

- Registo de informações e utilização dos instrumentos criados para caracterização da população alvo e de avaliação dos resultados do projecto em cada pessoa envolvida - ganha uma cultura baseada na oralidade que desvaloriza a escrita e faz rejeitar os "papéis".

- Participação de todas nas acções de formação específica do Projecto - a policronia dos tempos dificulta a concentração numa só tarefa e a dispersão, por vezes, impera.

Para além destas questões, aqui traduzidas em curtos apontamentos, e como em qualquer outra parceria que se pretende consolidada, o Projecto apostou, tempo e energia, na construção de algo colectivo em detrimento de um somatório de vários "nossos projectos" o que, inicialmente, não se revelou tarefa fácil. Algumas das acções (nomeadamente as de formação específica dirigidas aos elementos da AMUCIP) foram entendidas como uma ingerência e só mais tarde reconhecidas como uma mais valia, sendo que para tal contribuiu a abertura destas pessoas ciganas a ideias e propostas que não sendo suas acabaram por delas positivamente se apropriarem e o engenho e arte das pessoas não ciganas que souberam tornar clara e interessante a pertinência e importância destas acções.

Os termos e os conceitos tanto do Projecto, como da própria iniciativa EQUAL, têm sido sistematicamente tema de discussão no seio das reuniões de parceria, contribuindo-se para uma linguagem que, a pouco e pouco, se vai tornando comum, até pela insistência na invocação e na prática coerente do lema EQUAL "De Igual Para Igual".

O desafio tem sido, no entanto, para todos os elementos, na medida em que este é, por excelência, um contexto de aprendizagem e qualquer processo de aprendizagem transporta consigo renovação pessoal (e organizacional).

Estes desafios são, no entanto, entendidos como aliciantes já que são enfrentados num clima de confiança que se tem conquistado e para o qual tem contribuído a forma de gestão do orçamento do Projecto. Financiado na base da "despesa efectuada e paga", o Projecto tem trazido à AMUCIP alguns momentos de estrangulamento financeiro que só têm sido ultrapassadas graças à transferência de dinheiros próprios de outra organização da parceria, numa óptica de "gestão solidária" e de responsabilidade colectiva pela viabilidade de uma organização.

Ainda que não isenta de momentos de conflito e de tensão, esta tem sido uma parceria que se reforça na diversidade e que progride com as suas próprias discussões, por vezes tão longas, inesperadas e caóticas, que talvez a expressão mais adequada para a definir esteja nas palavras confiantes e orgulhosas de um dos elementos da AMUCIP "A nossa PD é uma comédia!".

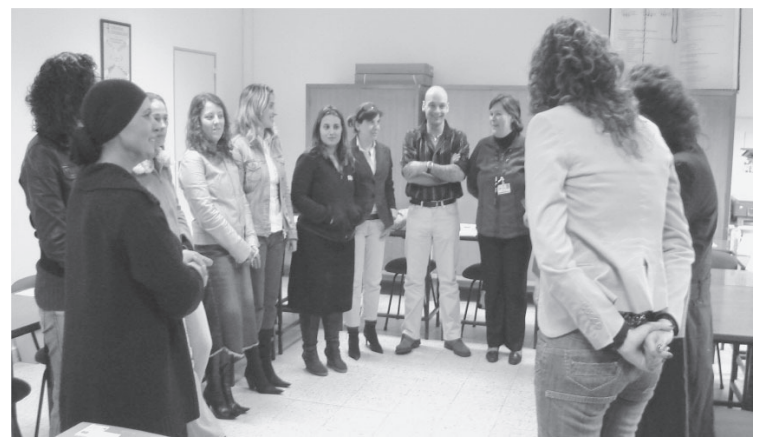




\section{Bibliografia}

AMIGUINHO, Abílio, 1993, Caracterização sociodemográfica e cultural da comunidade cigana no Alentejo, Relatório de Investigação, CRSS do Alentejo.

ACIME, 1997, Relatório do Grupo de Trabalho para a Igualdade e Inserção dos Ciganos, policopiado.

AMUCIP, 2006, Tomar a Palavra - Olhares e Falas de Mulheres Ciganas Portuguesas Sobre a Família e o Trabalho.

Comissão Europeia, 2004, The Situation of Roma in an Enlarged European Union, Directorate - General Employment \& Social Affairs, Luxemburgo.

Comissão Nacional do Rendimento Mínimo, 1998, "Comunidades Ciganas e Inserção Social no âmbito do RMG" in $1 .{ }^{\circ}$ Econtro: Reflectir para Agir, documento policopiado.

Conselho da Europa, 2005, On the Human Rigths Situation of the Roma, Sinti and Travellers in Europe, documento on line.

CORTESÃO, Luiza, et al., 2005, Pontes para Outras Viagens. Escola e Comunidade Cigana: representações recíprocas, ACIME, Lisboa.

CRUZ, Isabel, 2004, A intervenção precoce com a família cigana e suas crianças, dissertação de Mestrado em Comunicação em Saúde, Universidade Aberta, Lisboa.

DUARTE, Isabel et al., 2005, Os ciganos vistos pelos outros: proximidade social em espaços de coexistência inter-étnica Relatório de Investigação, CET/FCT.
DIAS, Eduardo Costa, et al., 2006, Comunidades Ciganas. Representações e dinâmicas de exclusão/integração, ACIME, Lisboa.

MONTENEGRO, Mirna (Org.), 1999, Ciganos e Educação, Cadernos ICE n. ${ }^{\circ}$, Setúbal: ICE.

PINTO, Maria de Fátima, 2000, A Cigarra e a Formiga: contributos para a reflexão sobre o entrosamento da minoria étnica cigana na sociedade portuguesa, Cadernos REAPN, Porto.

QUINTIN, Odile, 2005, Roma Challenges in the World of Education and Media, European Parliament Roma Forum, Bruxelas.

REIS, Fernanda (coord.), 1999, O Jovem Cigano e a Formação - Atitudes e expectativas face ao mercado de trabalho, Secretariado Diocesano de Lisboa da Obra Nacional para a Pastoral dos Ciganos.

SILVA, Luísa Ferreira da, e Magano, Olga, 2000, "A Integração/Exclusão Social de uma comunidade cigana residente no Porto" in IV Congreso Português de Sociologia Sociedade Portuguesa: Passados recentes, Futuros Próximos, Universidade de Coimbra.

SILVA, Luísa Ferreira da, Saúde/doença é questão de cultura: Atitudes e comportamentos de saúde materna das mulheres Ciganas em Portugal, documento policopiado. 